\title{
Saint-Vulbas - 140 chemin du Lavoir
}

\section{Stéphane Brouillaud}

\section{OpenEdition \\ Journals}

Édition électronique

URL : http://journals.openedition.org/adlfi/14485

ISSN : 2114-0502

Éditeur

Ministère de la culture

Référence électronique

Stéphane Brouillaud, "Saint-Vulbas - 140 chemin du Lavoir », ADLFI. Archéologie de la France Informations [En ligne], Rhône-Alpes, mis en ligne le 26 mars 2015, consulté le 03 mai 2019. URL http://journals.openedition.org/adlfi/14485

Ce document a été généré automatiquement le 3 mai 2019.

(C) Ministère de la Culture et de la Communication, CNRS 


\title{
Saint-Vulbas - 140 chemin du Lavoir
}

\author{
Stéphane Brouillaud
}

Lien Atlas (MCC) :

http://atlas.patrimoines.culture.fr/atlas/trunk/index.php?

ap_theme=DOM_2.01.02\&ap_bbox=5.232;45.784;5.302;45.862

1 La prescription du SRA a été motivée par la construction d'une maison individuelle située «Au village », 140 chemin du lavoir à Saint-Vulbas. La parcelle sise dans la zone de saisine archéologique fait partie intégrante d'un secteur connu pour ses nombreuses découvertes gallo-romaines. À l'issue de l'intervention archéologique, un angle de murs assez récupérés associé à un sol en mortier blanc gallo-romain a été mis au jour. La petitesse de la parcelle ne nous a pas permis de dégager les vestiges de manière extensive. Cependant, ces nouvelles découvertes viennent confirmer la présence et la continuité de l'occupation gallo-romaine dans ce secteur du village.

\section{INDEX}

Index géographique : Rhône-Alpes, Ain (01), Saint-Vulbas

Keywords : Antiquity

Mots-clés : mur, sol

operation Opération préventive de diagnostic (OPD), 2013 - nºA : 2211326

Index chronologique : Gallo-romain 


\section{AUTEURS}

\section{STÉPHANE BROUILLAUD}

Organisme de rattachement : Inrap 